\title{
Effect of $0.5 \%$ Chitosan mouthwash on recurrent aphthous stomatitis: a randomized double-blind crossover clinical trial
}

\author{
Fatemeh Rahmani ${ }^{1}$, Ali Akbar Moghadamnia ${ }^{2}$, Sohrab Kazemi $^{3}$, Atena Shirzad ${ }^{4}$, Mina Motallebnejad $^{5}$
}

${ }^{1}$ DDS of Oral and Maxillofacial Medicine, Avicenna Medical Center, Mazandaran University of Medical Sciences, Sari, Iran

${ }^{2}$ Ph.D. of Pharmacology\& Toxicology, Professor, Faculty of Medicine, Neuroscience Research Center, Health Research Institute, Babol University of Medical Sciences, Babol, Iran

${ }^{3}$ Ph.D. of Pharmaceutics Sciences, Faculty of Medicine, Neuroscience Research Center, Health Research Institute, Babol University of Medical Sciences, Babol, Iran

${ }^{4}$ DDS of Oral and Maxillofacial Medicine, Assistant Professor, Faculty of Dentistry, Babol University of Medical Sciences, Babol, Iran

${ }^{5}$ DDS of Oral and Maxillofacial Medicine, Professor, Faculty of Dentistry, Oral Health Research Center, Babol University of Medical Sciences, Babol, Iran

\section{Type of article: Original}

\begin{abstract}
Background: Recurrent aphthous stomatitis (RAS) is one of the most common painful oral lesions of which there is no certain treatment.

Objective: The aim of this study was to determine the effect of Chitosan mouthwash $0.5 \%$ on RAS.

Methods: This randomized double-blind crossover clinical trial was conducted at a dental school in Babol, Iran, from 2015 to 2016 . Twenty patients with a history of minor aphthous stomatitis were entered into this study. All patients were initially monitored in the first episode without treatment, and then were randomly treated in three other episodes with Chitosan, Triamcinolone or Biogel mouthwashes. The ulcer size and pain intensity by using visual analogous score (VAS) were recorded in each episode. Data were analyzed by ANOVA and Tukey test. We used SPSS version 20 to analyze data.

Results: The mean ulcer size on the fifth day ( $\mathrm{p}=0.026, \mathrm{p}=0.042$, respectively) and VAS on the third and fifth days $(p=0.011, p=0.013$, respectively) were significantly less in Triamcinolone and Chitosan groups than Biogel and the no treatment episode. There were no significant differences between Chitosan and Triamcinolone groups in the average ulcer size and pain intensity in all the examination days.

Conclusions: Chitosan mouthwash is effective on pain relief and reducing ulcer size of minor aphthous stomatitis and this effect is almost the same as Triamcinolone mouthwash.

Clinical trial registration: The study was registered and approved by Iranian Registry of Clinical Trials (http://www.irct.ir) with IRCT ID: IRCT2015030718753N2.

Funding: The study was funded by Deputy of Research and Technology of Babol University of Medical Sciences (ref. no.: 9133625).

Keywords: Recurrent aphthous stomatitis, Chitosan, Triamcinolone, Mouthwash
\end{abstract}

\section{Introduction}

Recurrent aphthous stomatitis (RAS) is one of the most common painful oral conditions, which manifests as small, multiple, recurrent, round or ovoid circumscribed ulcers with yellow or gray color (1). The prevalence of RAS varies from 5 to $66 \%$. Although the lesion is self-limiting, it causes pain and interferes with eating, speaking and

\section{Corresponding author:}

Professor Dr. Mina Motallebnejad, Faculty of Dentistry, Oral Health Research Center, Babol University of Medical Sciences, Babol, Iran. Tel: +98.9111114191, Email: mmotallebnejad@yahoo.com

Received: January 15, 2017, Accepted: May 08, 2018, Published: June 2018

iThenticate screening: May 08, 2018, English editing: May 14, 2018, Quality control: May 15, 2018

This article has been reviewed / commented by four experts

Ethics approval: MUBABOL.REC.1393.17, February 03, 2015

(C) 2018 The Authors. This is an open access article under the terms of the Creative Commons Attribution-NonCommercialNoDerivs License, which permits use and distribution in any medium, provided the original work is properly cited, the use is non-commercial and no modifications or adaptations are made. 
swallowing so an efficient therapeutic strategy is required (2). There is no certain treatment for the recurrent aphthous stomatitis, but topical and systemic medications can be used in its management (3). Topical agents include anti-inflammatories, analgesics, antibiotics and corticosteroids. Triamcinolone acetonide is used in the form of ointment in solitary ulcers and as mouthwash in multiple lesions (4). As corticosteroids are known to get absorbed systemically even on topical application, they can lead to certain adverse reactions. So nowadays, herbal medicines are gaining more attention due to their decreased side effects. Chitosan is a natural polysaccharide prepared from deacetylation of chitin. Chitin is naturally found in the shell of crustaceans such as shrimp and crab (5). Chitosan has many biological properties such as biocompatibility, biodegradability, lack of allergenicity (6), non-toxic (5), renewable, film-forming ability and moisturizing (7). Chitin and Chitosan is said to have potent analgesic effects (8). One of the main properties of polymer is its antimicrobial activity which acts against a variety of microorganisms including viruses (7), fungi, bacteria and algae (9). There are many studies which show that Chitosan has analgesic $(8,10)$ and wound healing $(11,12)$ effects. Since Chitosan has analgesic, wound-healing, non-toxic, biocompatibility and biodegradable properties, the aim of this study was to evaluate the effect of Chitosan on oral recurrent aphthous stomatitis and compare its effect with Triamcinolone.

\section{Material and Methods}

\subsection{Research design and ethics}

This randomized double-blind crossover clinical trial was conducted at a dental school in Babol, Iran, from 2015 to 2016. The trial was approved by the Ethics Committee of Research at Babol University of Medical Sciences (ref. no.: MUBABOL.REC.1393.17, February 03, 2015), and registered at the Iranian Registry of Clinical Trials with the IRCTID: IRCT2015030718753N2. All participants signed the written informed consent before entering the study.

\subsection{Participants and selection criteria}

Twenty patients ( 8 men and 12 women) aged 18-50 years were selected among the patients referred to the Department of Oral Medicine School. They all had a history of minor recurrent aphthous stomatitis in labial or buccal mucosa at least four episodes per year. Exclusion criteria consisted of the following: a) patients with the history of any systemic disease causing oral ulcers, gastrointestinal disorders (Crohn's disease, ulcerative colitis), Behcet's syndrome, Reiter's syndrome, hematologic disorders, malnutrition, allergic conditions, b) receiving chemotherapy, immunosuppressive drugs or corticosteroids in the last year c) patients with other mucosal lesions, d) pregnant and lactating women, and e) patients whose normal healing of aphthous ulcers was usually in less than 5 days. Figure 1 shows the study flow diagram based on the CONSORT 2010.

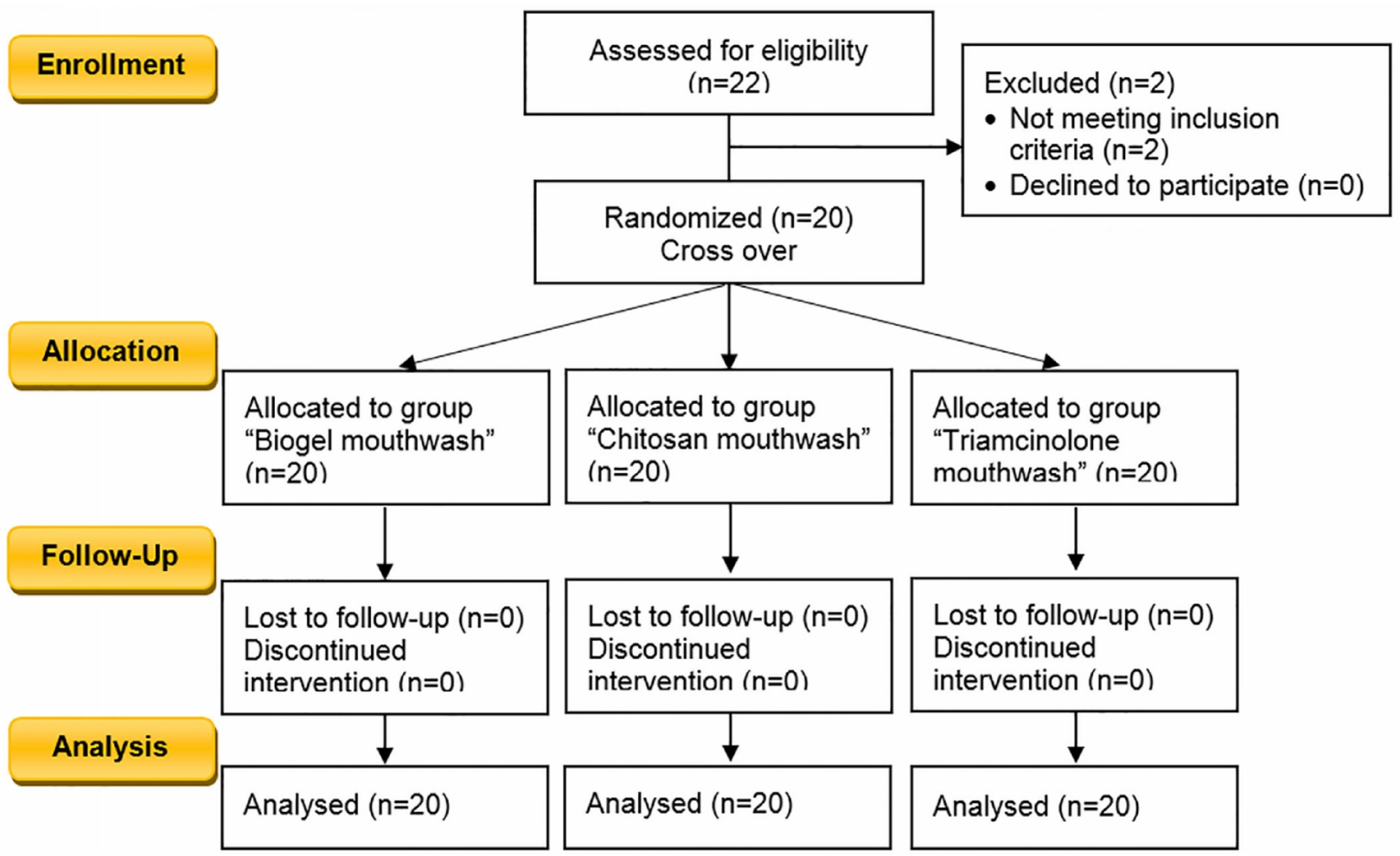

Figure1. CONSORT flow diagram of the trial 


\subsection{Mouthwash Preparation}

For the preparation of Biogel, $95 \mathrm{cc}$ of distilled water was transferred to a $500 \mathrm{cc}$ beaker, and placed on a hot plate stirrer. Then the required carbopol was added to water and heated. After that, the methyl paraben and propyl paraben were dissolved in $95 \%$ alcohol and the solution was added to the beaker, too. Finally, the required amount of glycerin was added to the sample. Then 0.5 grams of effective ingredients of Chitosan (Germany, Sigma-Aldrich, LMW: wt 50000-190000) or triamcinolone (Iran) emulsion were added to this base gel per $100 \mathrm{ml}$ of gel for preparing the Chitosan and triamcinolone mouthwashes. Finally, $0.5 \%$ mouthwash with $\mathrm{PH}=5.5$ was prepared.

\subsection{The study protocol}

The records, which include individual information and characteristics of ulcers (pain, ulcer area, duration of healing and effective index EI) were filled out for each patient. Oral examinations were conducted by one examiner in the Department of Oral Medicine. The patients were asked to refer 24 hours after appearance of aphthous ulcers. All patients were studied during 4 periods of aphthous ulcer. In the first period, they were only monitored without the use of mouthwash or any other treatment. Pain intensity, ulcer area and healing time were recorded in any visits. In the other three episodes, one of Chitosan, Triamcinolone or Biogel mouthwashes was randomly given to the patients. Randomization was performed in the first session of examination in the first period, using random cards for each patient. All bottles of mouthwash were coded by a pharmacologist so that the examiner and the patients were unaware of the contents of drugs (double-blind). The patients were instructed to keep $5 \mathrm{cc}$ mouthwash for 4 minutes in the mouth and then spit it out 3 times a day after each meal. All patients in 4 periods were examined on the first, third, fifth and seventh day by the examiner. Moreover, if the ulcer healed at any time prior to the examinations, further examinations would not be performed and if no improvement was achieved on the seventh day, use of the mouthwash would continue, and the patient was examined again on the tenth day. Ulcer diameter and pain level were measured in the first and all subsequent examination days. Ulcer diameter was measured using Iwanson gauge (ARTMAN Brand Wise Linkers USA) with $0.1 \mathrm{~mm}$ accuracy in the maximum and minimum diameters, and the wound area was calculated using a mathematical formula based on the wound shape (circle or oval). Pain was numerically valued from 0 to 10 using visual analog scale (VAS). For patients, the number 0 and 10 were considered as no pain and the worst pain, respectively. Sugar-free orange juice (Takdaneh Iran) was used as the stimulus of pain. The healing time based on pain relief $(\mathrm{VAS}=0)$ and wound healing and absence of pseudo membranous layer were recorded as the number of days in all 4 periods for each patient. The effectiveness index (EI) for ulcer size and pain relief was calculated through the following formula:

$\mathrm{EI}=[(\mathrm{V} 1-\mathrm{V} 3$ or $\mathrm{V} 5$ or $\mathrm{V} 7$ or $\mathrm{V} 10) / \mathrm{V} 1] \times 100$;

Where: V1 means the value of the baseline and V3, V5, V7 and V10 means the values of the $1^{\text {st }}, 3^{\text {rd }}, 5^{\text {th }}, 7^{\text {th }}$ and $10^{\text {th }}$ days. Effectiveness indices were ranked as follows: 1) Healed: EI $\geq 95 \%$, 2) Marked improvement: $70>\mathrm{EI}<95 \%$, 3) Moderate improvement: $30 \%<\mathrm{EI}<70 \%$, 4) No improvement: EI $<30 \%$ (13). Adverse effects of drugs based on the complaints of patient and clinical examination were recorded. At the end of each episode of using mouthwash, the patient's satisfaction with the treatment regimen were recorded with the question of "Overall, how satisfied are you with your treatment?" and their selection of one of the items such as very good, good, moderate, poor and very poor.

\subsection{Data Analysis}

Data were analyzed by SPSS version 17 (SPSS Inc., Chicago, Illinois, USA), using ANOVA and Tukey test.

\section{Results}

Twenty patients ( 8 men and 12 women) with the mean age of $35.15 \pm 9.8$ and with history of minor aphthous stomatitis were entered into the study. In addition, all patients were evaluated during 4 periods of aphthous ulcers.

\subsection{Ulcer size}

As shown in Figure 2, there was no significant difference in mean ulcer size between Chitosan and Triamcinolone groups on any day of the examination $(\mathrm{p}=0.09)$. On the first day of the examination, no significant difference $(\mathrm{p}=0.8)$ was observed in mean ulcer size among the groups. On the third day, the Triamcinolone group indicated smaller ulcer size than the episode of no treatment $(\mathrm{p}=0.011)$ and no significant differences were observed in other groups. On the fifth day, Triamcinolone and Chitosan groups had less ulcer size compared to no treatment episode $(\mathrm{p}<0.0001)$ and also to the Biogel group $(\mathrm{p}=0.026, \mathrm{p}=0.042$, respectively). On the seventh day, the Triamcinolone and Chitosan groups had less ulcer size than the other two groups, but this difference was not significant compared to the Biogel group. On the tenth day, all three groups compared to the no treatment episode showed a significant decrease in ulcer size $(\mathrm{p}=0.04)$. 


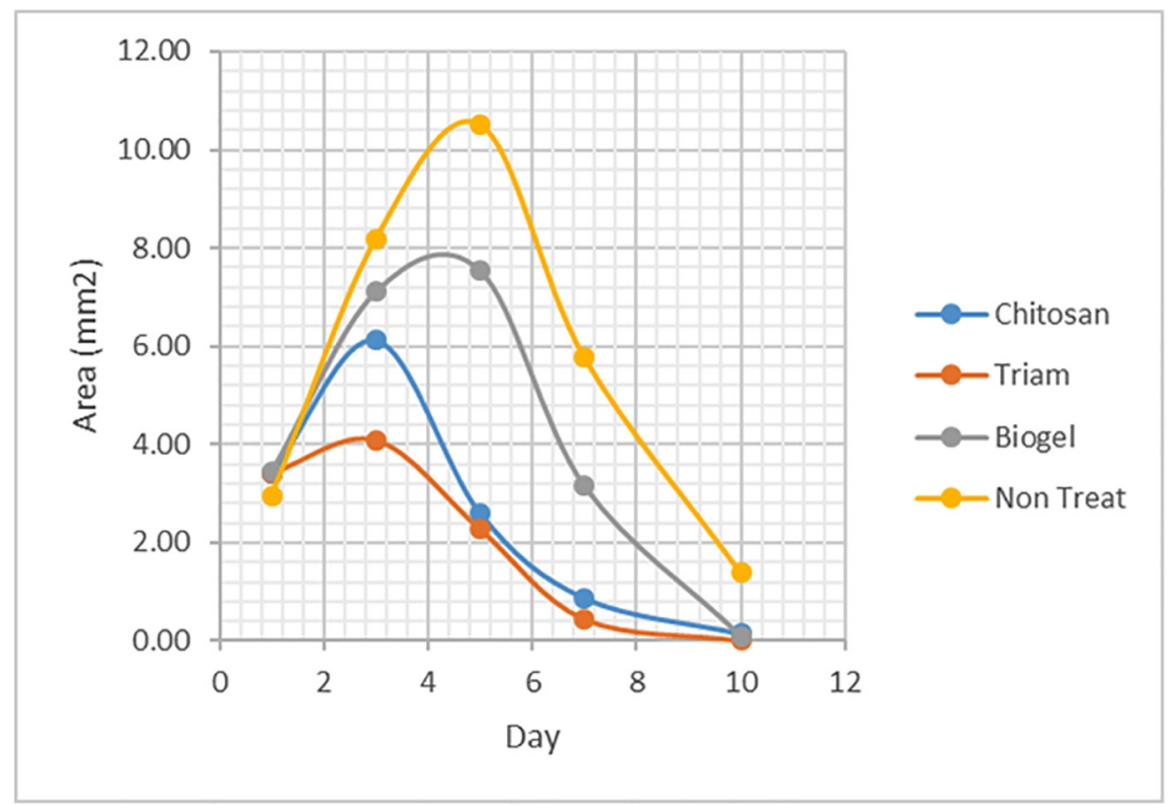

Figure 2. The mean of ulcer size of three mouthwash groups and no treatment episode.

\subsection{Pain intensity (VAS)}

According to Figure 3, the mean of VAS in Chitosan and Triamcinolone groups were not significantly different on all examination days. On the first day, the difference of VAS between the groups was not significant $(\mathrm{p}=0.35)$. On the third and fifth day, the VASs were lower in Triamcinolone and Chitosan groups than in the no treatment episode and Biogel group $(\mathrm{p}=0.01)$. On the seventh day, all three groups compared to the no treatment episode had significant pain relief $(\mathrm{p}=0.02)$.

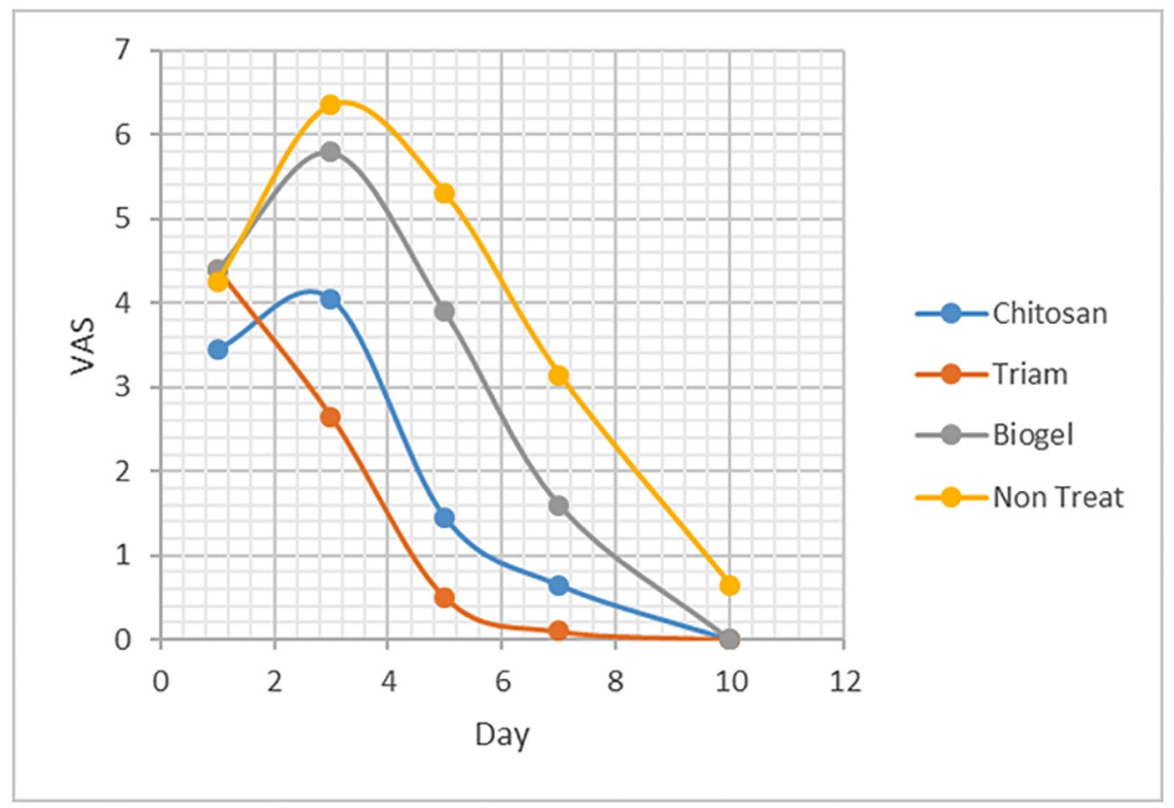

Figure 3. Mean of VAS in mouthwash groups and no treatment episode.

\subsection{Healing time and patient satisfaction}

The mean of healing time for Chitosan, Triamcinolone and Biogel groups were (6.2 \pm 1.82$),(5.15 \pm 1.42)$ and $(8.3 \pm 1.62)$ days, respectively. The means of healing time for Chitosan and Triamcinolone groups were almost the same $(\mathrm{p}=0.310)$ while they were significantly lower than the Biogel group ( $\mathrm{p}=0.005$ and $\mathrm{p}<0.0001$, respectively). 
The mean rates of satisfaction were $(3.05 \pm 0.6),(3.45 \pm 0.6)$ and $(2.05 \pm 0.76)$ for Chitosan, Triamcinolone and Biogel groups, respectively (Figure 4). The mean satisfaction rate of Biogel was significantly lower than Chitosan and Triamcinolone $(p<0.0001)$ and satisfaction rate of Chitosan and Triamcinolone were almost the same $(p=0.144)$.

\subsection{Effectiveness index (EI)}

To assess the improvement, EI was individually calculated for ulcer size and VAS and eventually, the mean of both EIs was calculated and named overall EI. As shown in Figure 4, mean EI of ulcer size on the third day was negative only for Triamcinolone, Chitosan and Biogel mouthwash. Mean EI of ulcer size on the seventh and tenth days were "healed" for Triamcinolone and Chitosan, and was "moderate improvement" for Biogel on the tenth day. In addition, EI was calculated for VAS as illustrated in Figure 5. Similarly, mean EI on the third day was negative for Chitosan and Biogel groups. Mean EI on the seventh day was "healed" for Triamcinolone and Chitosan, and for all groups on the tenth day. The mean of overall EI presented in Figure 6, had similar results too.

\subsection{Adverse effects}

No serious adverse effects such as increased sensitivity, pain, infection, or any mucosal lesion were reported by patients following the use of mouthwash. However, one patient (5\%) felt mild throat sore after applying Chitosan mouthwash and bad taste 20 minutes after using the Biogel mouthwash but it did not cause excluding the patient from the study.

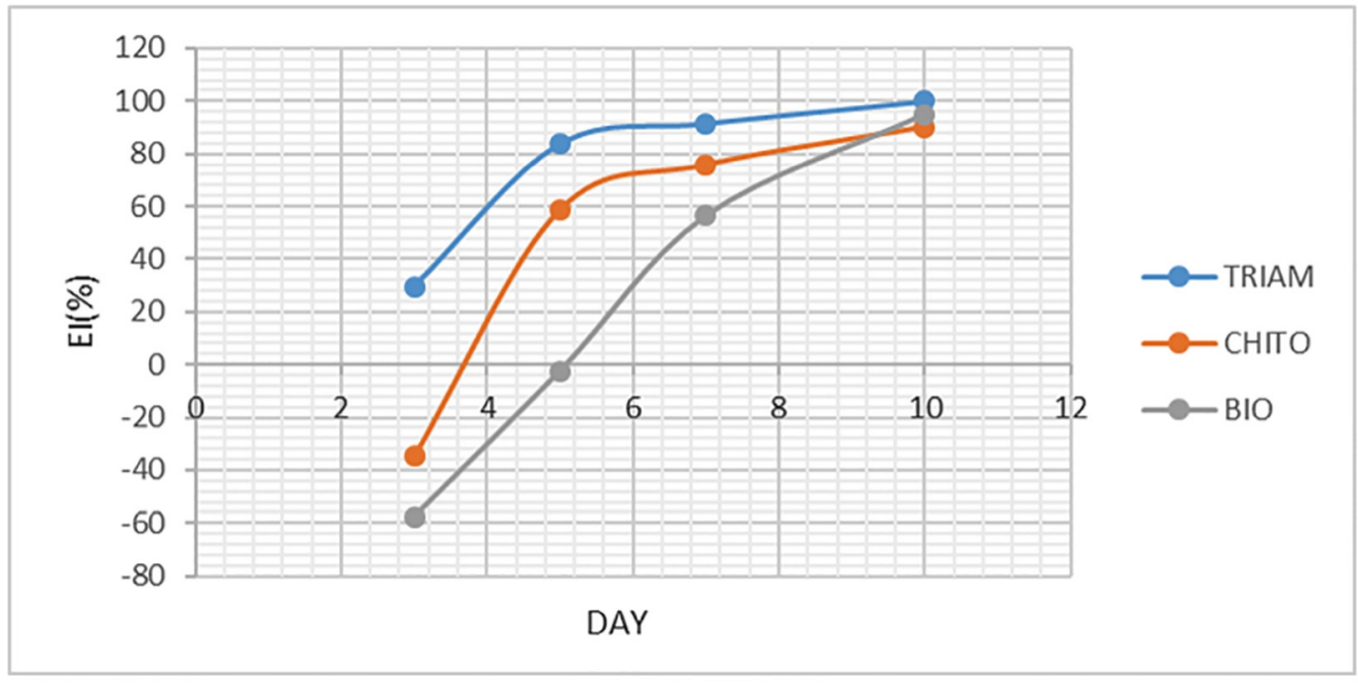

Figure 4. Comparison of the mean of pain EI of three mouthwashes

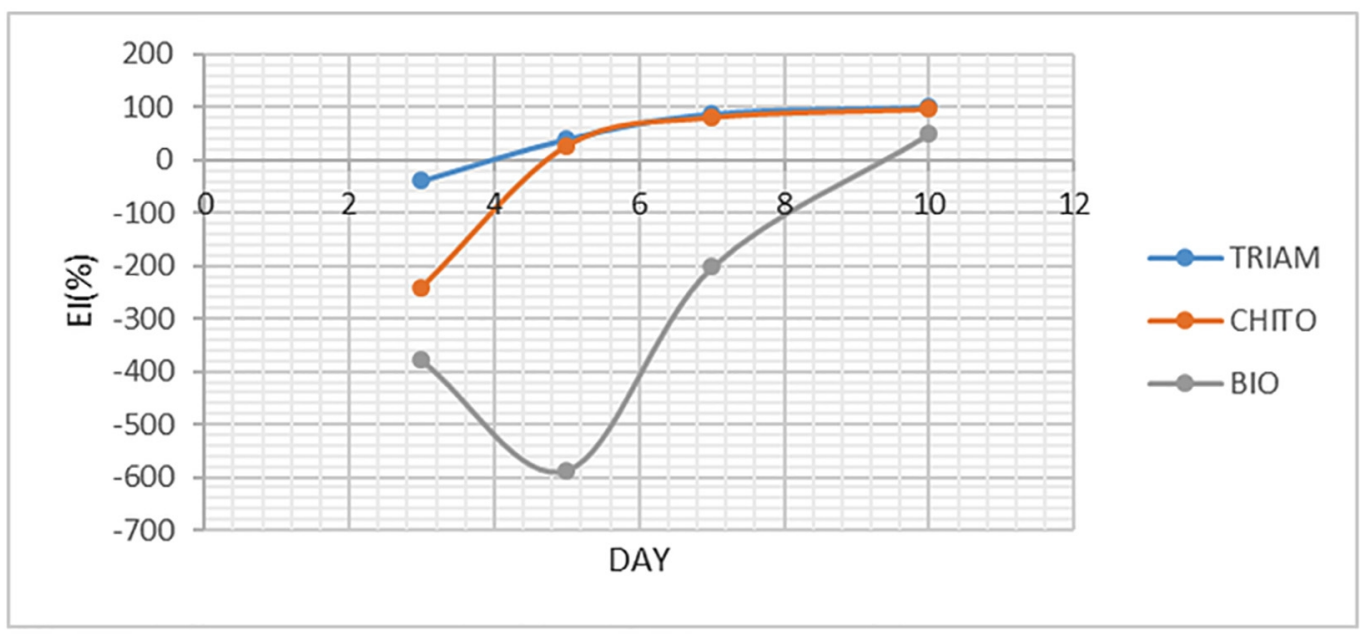

Figure 5. The mean EI of ulcer size of three mouthwashes 


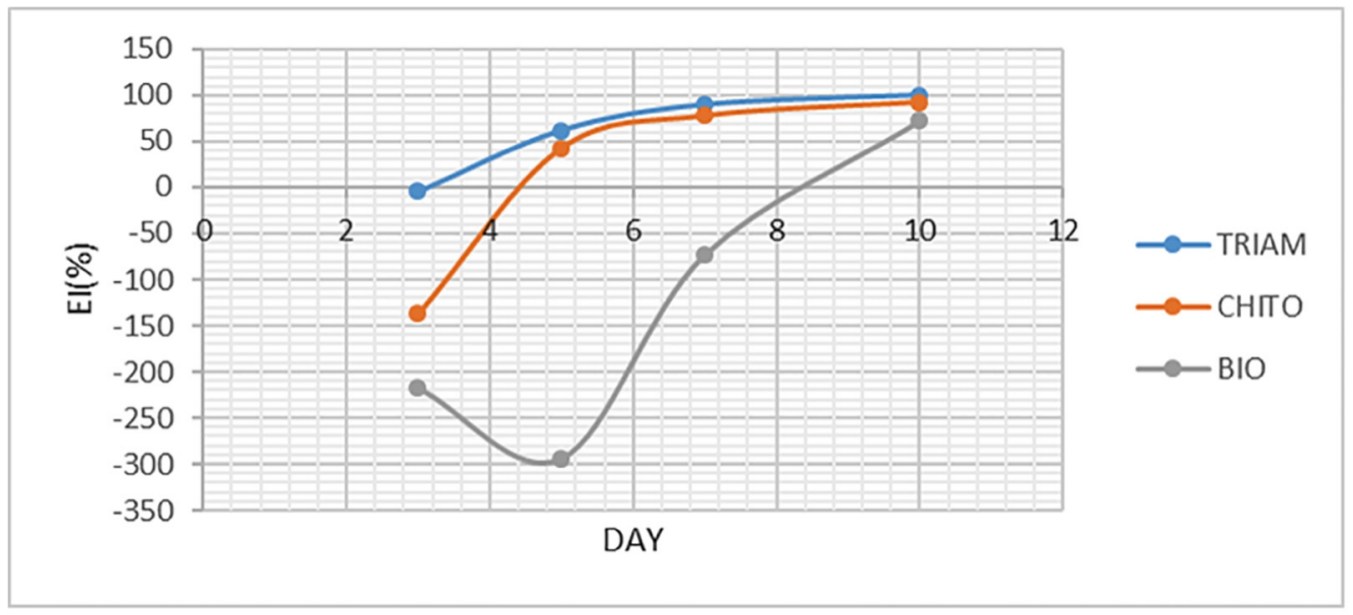

Figure 6. The mean of overall EI of three mouthwashes

\section{Discussion}

The results of this clinical trial showed that Chitosan mouthwash $0.5 \%$ compared to a no treatment episode and Biogel mouthwash led to a reduction in the ulcer size and pain relief and showed similar effects with Triamcinolone (5\%) mouthwash. These findings confirm the results of previous studies which suggested the analgesic and wound healing properties of Chitosan. Although recurrent aphthous stomatitis is self-limiting lesions, it causes pain and difficulty in eating, speaking and swallowing, so an efficient therapeutic strategy is required (2). The aim of all available topical or systemic treatments is relieving the pain, reducing the dysfunction and inhibiting the acute inflammatory reaction (14). The first choice of treatment is topical agents (15). Thus, several studies have been conducted to find the topical agents with high impact and low side effects. Chitosan is a polymer with antimicrobial activity, and many researchers have reported its wide range of antimicrobial activity against fungi, aerobic and anaerobic bacteria with high biocompatibility and low toxicity (6). Bae et al. showed that Chitosan inhibits the growth of microorganisms associated with oral disease and biofilm formation (16). Costa et al. reported in vitro and in vivo lower toxicity and higher antimicrobial activity of Chitosan mouthwash than commercial mouthwashes (6, 17). Bacteria and their metabolites which were often identified in aphthous ulcers can aggravate the ulcers. The effect of antibacterial therapy in the treatment of recurrent aphthous stomatitis has been proven (14). In the current study, the reduction of ulcer size in the Chitosan group may be due to the effective antibacterial properties of Chitosan and its acceleration in ulcer improvement. The pain of aphthous ulcer is created by the high inflammatory stimulation of afferent nerve endings at the junction of epithelial and subepithelial. Thus, the anti-inflammatory agents are considered as the first-line to control the symptoms of recurrent aphthous stomatitis (14). In the current study, we observe the analgesic effect of Chitosan. Huang et al. (10) and Y. Okamoto et al. (8) also suggested the analgesic properties of Chitosan. Huang represented that the concentration of bradykinin (a physiologic mediator of pain) in carboxymethyl chitosan-treated group was significantly lower than the control group and this indicates the analgesic and anti-inflammatory effect of carboxymethyl chitosan (10). Chitosan mouthwash showed better effect in reducing ulcer size than the Biogel group which confirms wound healing effect. Chitosan activates the inflammatory and immune cells such as polymorphonuclears, macrophages, fibroblasts and the angioendothelial cells and promote the wound healing process (11). All results of using Triamcinolone mouthwash which is a corticosteroid with moderate to strong effect (18) including pain relief, reduction of ulcer size and the mean of healing time were better than those of using two other mouthwashes, and patients reported the most satisfaction with this mouthwash, which supports the fact that corticosteroids are one of the main treatment strategies of recurrent aphthous stomatitis (18). However, the difference in ulcer size reduction, pain relief, healing time and satisfaction rate was not significant between Triamcinolone and Chitosan mouthwashes, and based on this study, it can be concluded that the effect of Chitosan is similar to that of Triamcinolone in management of recurrent aphthous stomatitis. EI was lower in Chitosan mouthwash than Triamcinolone in the early days, while it increased later and it would be almost similar to the Triamcinolone group. So, the effects of Chitosan would appear later than Triamcinolone.

\section{Conclusions}

The present study demonstrated that Chitosan has the analgesic effects and promotes the wound healing process, and its mouthwash is safe and effective for management of recurrent aphthous stomatitis. This effect is almost similar to that of Triamcinolone which is recognized as the treatment of recurrent aphthous stomatitis. 


\section{Acknowledgments and funding:}

Hereby, the authors would like to thank the Deputy of Research and Technology of Babol University of Medical Sciences for the financial support of the project (ref. no.: 9133625).

\section{Registration:}

The study was registered and approved by Iranian Registry of Clinical Trials (http://www.irct.ir) with IRCT ID: IRCT2015030718753N2.

\section{Conflict of Interest:}

There is no conflict of interest to be declared.

\section{Authors' contributions:}

All authors contributed to this project and article equally. All authors read and approved the final manuscript.

\section{References:}

1) Jurge S, Kuffer R, Scully C, Porter SR. Mucosal disease series. Number VI. Recurrent aphthous stomatitis. Oral diseases. 2006; 12(1): 1-21. doi: 10.1111/j.1601-0825.2005.01143.x. PMID: 16390463.

2) Gallo Cde B, Mimura MA, Sugaya NN. Psychological stress and recurrent aphthous stomatitis. Clinics (Sao Paulo). 2009; 64(7): 645-8. doi: 10.1590/S1807-59322009000700007. PMID: 19606240, PMCID: PMC2710437.

3) Preeti L, Magesh K, Rajkumar K, Karthik R. Recurrent aphthous stomatitis. Journal of oral and maxillofacial pathology: JOMFP. 2011; 15(3): 252-6. doi: 10.4103/0973-029X.86669.

4) Belenguer-Guallar I, Jimenez-Soriano Y, Claramunt-Lozano A. Treatment of recurrent aphthous stomatitis. A literature review. J Clin Exp Dent. 2014; 6(2): e168-74. doi: 10.4317/jced.51401. PMID: 24790718, PMCID: PMC4002348.

5) Ji QX, Zhong de Y, Lu R, Zhang WQ, Deng J, Chen XG. In vitro evaluation of the biomedical properties of chitosan and quaternized chitosan for dental applications. Carbohydrate research. 2009; 344(11): 1297 302. doi: 10.1016/j.carres.2009.05.014. PMID: 19535044.

6) Costa EM, Silva S, Madureira AR, Cardelle-Cobas A, Tavaria FK, Pintado MM. A comprehensive study into the impact of a chitosan mouthwash upon oral microorganism's biofilm formation in vitro. Carbohydrate polymers. 2014; 101: 1081-6. doi: 10.1016/j.carbpol.2013.09.041. PMID: 24299877.

7) Rinaudo M. Chitin and chitosan: Properties and applications. Progress in Polymer Science. 2006; 31(7): 603-32. doi: 10.1016/j.progpolymsci.2006.06.001.

8) Okamoto Y, Kawakami K, Miyatake K, Morimoto M, Shigemasa Y, Minami S. Analgesic effects of chitin and chitosan. Carbohydrate polymers. 2002; 49(3): 249-52. doi: 10.1016/S0144-8617(01)00316-2.

9) Maria M, Carvalho SG, Stamford TCM, Santos EP, Tenório P, Sampaio F. chitosan as an oral antimicribial agent. Mendez-Vilas A, editor. badajoz: Formatex Research Center; 2011.

10) Huang S, Han B, Shao K, Yu M, Liu W. Analgesis and wound healing effect of chitosan and carboxymethyl chitosan on scaled rats. Journal of Ocean University of china. 2014; 13(5): 837-41. doi: $10.1007 / \mathrm{s} 11802-014-2285-2$.

11) Ueno H, Mori T, Fujinaga T. Topical formulations and wound healing applications of chitosan. Advanced Drug Delivery Reviews. 2001; 52(2): 105-15. doi: 10.1016/S0169-409X(01)00189-2. PMID: 11718934.

12) Kilic C, Gulec Peker EG, Acarturk F, Kilicaslan SM, Coskun Cevher S. Investigation of the effects of local glutathione and chitosan administration on incisional oral mucosal wound healing in rabbits. Colloids Surf B Biointerfaces. 2013; 112: 499-507. doi: 10.1016/j.colsurfb.2013.08.050. PMID: 24119774.

13) Zhou Y, Chen Q, Meng W, Jiang L, Wang Z, Liu J, et al. Evaluation of penicillin G potassium troches in the treatment of minor recurrent aphthous ulceration in a Chinese cohort: a randomized, double-blinded, placebo and no-treatment-controlled, multicenter clinical trial. Oral Surg Oral Med Oral Pathol Oral Radiol Endod. 2010; 109(4): 561-6. doi: 10.1016/j.tripleo.2009.11.006. PMID: 20188604.

14) Jiang XW, Zhang Y, Song GD, Li FF, Peng HY, Yang SK, et al. Clinical evaluation of allicin oral adhesive tablets in the treatment of recurrent aphthous ulceration. Oral Surg Oral Med Oral Pathol Oral Radiol Endod. 2012; 113(4): 500-4. doi: 10.1016/j.00oo.2011.09.007. PMID: 22668427.

15) Tarakji B, Gazal G, Al-Maweri SA, Azzeghaiby SN, Alaizari N. Guideline for the diagnosis and treatment of recurrent aphthous stomatitis for dental practitioners. Journal of international oral health: JIOH. 2015; 7(5): 74-80. PMID: 26028911, PMCID: PMC4441245. 
16) Bae K, Jun EJ, Lee SM, Paik DI, Kim JB. Effect of water-soluble reduced chitosan on Streptococcus mutans, plaque regrowth and biofilm vitality. Clinical oral investigations. 2006; 10(2): 102-7. doi: 10.1007/s00784-006-0038-3. PMID: 16572330.

17) Costa EM, Silva S, Costa MR, Pereira M, Campos DA, Odila J, et al. Chitosan mouthwash: toxicity and in vivo validation. Carbohydr Polym. 2014; 111: 385-92. doi: 10.1016/j.carbpol.2014.04.046. PMID: 25037365.

18) Hamishehkar H, Nokhodchi A, Ghanbarzadeh S, Kouhsoltani M. Triamcinolone Acetonide Oromucoadhesive Paste for Treatment of Aphthous Stomatitis. Advanced pharmaceutical bulletin. 2015; 5(2): 277-82. doi: 10.15171/apb.2015.038. PMID: 26236668, PMCID: PMC4517075. 